\title{
O CONCEITO CIENTÍFICO DE PROGRESSO E OBJETIVIDADE E A SUA CRÍTICA POR NIETZSCHE
}

\author{
Peter Johann Mainka ${ }^{1}$
}

\section{RESUMO}

Na segunda metade do século XIX, as ciências que predominavam na Alemanha eram as ciências naturais sob a influência do Positivismo e as ciências históricas sob a influência do Historicismo. A base das suas ciências era o Objetivismo, que versava sobre a possibilidade de um conhecimento absoluto e objetivo da realidade. Ante estas tendências gerais da história da ciência no século XIX, a parte principal deste artigo apresenta a contribuição de Friedrich Nietzsche para essa discussão com base em sua Segunda Consideração Extemporânea de 1874, Sobre a utilidade e a desvantagem da história para a vida. - Nesse escrito, Nietzsche refletia, filosoficamente, como observador atento do seu tempo, sobre a história e historiografia, sempre estendendo as suas considerações às questões fundamentais da cultura e da educação, como das ciências em geral. $\mathrm{O}$ seu ponto de vista, portanto, ficava fora das ciências (históricas) e também acima delas. A base das suas reflexões era a vida presente e atual, o homem individual e ativo e a sua ação imediata. No âmago desses critérios, Nietzsche desenvolveu a sua crítica forte e radical das tendências culturais, educacionais e científicas do seu tempo. Quanto à teoria do conhecimento, Friedrich Nietzsche representa, com a sua crítica ao conhecimento absoluto e objetivo, uma ponte entre Immanuel Kant, no fim do século XVIII, e o início do século $\mathrm{XX}$, quando o pensamento kantiano, que versava sobre a possibilidade de somente um conhecimento relativo, foi retomado por Max Weber e representantes famosos das ciências naturais, mas a crítica nietzschiana não tinha efeitos naquele tempo.

Palavras-chave: Nietzsche, Friedrich; história das ciências, historiografia; epistemologia; século XIX.

\section{SCIENTIFIC CONCEPT OF PROGRESS AND OBJECTIVITY AND HIS CRITICISM BY NIETZSCHE}

\section{ABSTRACT}

In the second half of the $19^{\text {th }}$ century, the sciences predominating in Germany were the natural sciences, influenced by the positivism, and the historical sciences under the influence of the historicism. The base of these two sciences was the objectivism treating of the possibility of absolute and really objective knowledge. In view of these general tendencies in the history of science in the $19^{\text {th }}$ century, the main part of this article describes the contribution of Friedrich Nietzsche to that discussion, based on the second Untimely Meditation from 1874 On the Use and Abuse of History for Life. - In this article, Nietzsche as an attentive observer of his times, is thinking, philosophically, about history and historiography, including reflections about general questions of culture, education or the sciences at all. His point of view was outside of the (historical) sciences and also above them. The base for his reflections, were the present and actual life, the individual and active man and his immediate action. In the heart of his thoughts, Nietzsche develops his intense and radical critic of the contemporary cultural, educational and scientific tendencies. In epistemological relation, Friedrich Nietzsche represents a connection between Immanuel Kant, in the end of the $18^{\text {th }}$ century, and the beginning of the $20^{\text {th }}$ century, when the thoughts of Kant about the possibility of exclusively relative knowledge, were resumed by Max Weber and other famous representatives of the natural sciences, but the ideas of Nietzsche meets with no response in this time.

Keywords: Nietzsche, Friedrich; history of sciences; historiography; epistemology; $19^{\text {th }}$ century. 
Na filosofia de Friedrich Nietzsche (1844-1900) (MARTON, 1993; NEMEC, 1999; e GERHARDT, 1999), apesar de todas as alterações no decorrer dos seus quase 20 anos de força produtiva e da variedade dela nos seus pormenores, o momento e o fato, a presença e o ato nela têm uma importância fundamental. Daqui, ele desenvolve as suas ideias de uma concordância dos tempos de passado, presente e futuro, e observa os acontecimentos históricos no passado e a ocupação historiográfica dos homens com eles. Desse ponto de partida expressamente filosófico, do qual será tratado em seguida, a sua perspectiva é, fundamentalmente, diferente das discussões teórico-metodológicas das ciências históricas em geral e, especialmente, das reflexões contemporâneas sobre a teoria e a filosofia da história, dominadas pelo chamado Historicismo. Mesmo assim, também Nietzsche não pôde fazer as suas considerações acerca $D a$ utilidade e dos inconvenientes da História para a vida (no original alemão: Unzeitgemässe Betrachtungen. Zweites Stück. Vom Nutzen und Nachtheil der Historie für das Leben) (NIETZSCHE, 1988/1999, p. 234-334 e NIETSACHE, s/d, p. 101-205) ${ }^{2}$ completamente desligado do fundo histórico e cultural, no qual ele tinha crescido e vivia e que conhecia e observava minuciosamente. De uma consideração comparativa das duas áreas, isto é, dos pensamentos nietzschianos e do ambiente desse filósofo alemão, não há somente diferenças, mas algumas semelhanças. Por isso, em uma primeira parte, será apresentado o conceito tanto das ciências naturais e exatas no século XIX, especialmente na sua segunda metade, quanto das ciências históricas, as quais tiveram uma posição dominante no sistema científico naquele tempo. Em uma segunda parte, a posição específica de Nietzsche, contrapondo-se às tendências principais do seu próprio tempo.

Nietzsche era o mais famoso crítico das ciências e das suas respectivas teorias mais importantes na segunda metade do século XIX, que defendiam um otimismo científico quase ilimitado tanto nas ciências naturais e exatas quanto nas ciências históricas.

O característico das ciências naturais e exatas era, naquele tempo - e é ainda em nossos dias -, o Positivismo, uma doutrina metodológica e filosófica, estabelecida por Auguste Comte (1798-1857) (LEUSCHNER, 1968) e divulgada por seu amigo e discípulo Johan Stuart Mill (1806-1873) (RAUSCH, 1968). O Positivismo se baseia no Empirismo, ou seja, na observação e no experimento. Somente a observação empírica, podendo conceber as verdadeiras características da natureza e do mundo, produz conhecimentos. A observação sempre mais exata possibilita conhecimentos sempre mais exatos e, finalmente, o conhecimento das leis eternas da natureza. Nesse processo, baseia-se, exclusivamente, todo progresso da humanidade (OEXLE, 1984). O Positivismo pretende, portanto, conhecer a natureza verdadeiramente, isto é, objetivamente. Esse Objetivismo, no sentido ingênuo, de que conhecimentos refletem verdadeiramente realidades, representa a base da ciência positivista que reclama para si mesma a capacidade de efetivar unicamente o progresso humano.

Tal Positivismo e o otimismo das ciências na Alemanha e em toda a Europa da segunda metade do século XIX eram representados, excelentemente, por Rudolf Virchow (1821-1902), um famoso médico, reformador social e político na Prússia (SCHIPPERGES, 1999). Em consonância com Comte, de que as ciências positivistas já tinham a qualidade de uma religião (COMTE, 1983), também Virchow declarou várias vezes semelhante convicção, por exemplo, em 1873, quando ele disse perante a Assembleia dos naturalistas e médicos alemães: "Uma fé, temos também nós: a fé no progresso quanto ao conhecimento da verdade" (VIRCHOW apud OEXLE, 1984, p. 24). Os resultados das ciências naturais e exatas, reproduzindo autenticamente a verdade, podem melhorar a vida humana, evidentemente no sentido de um progresso permanente e com a pretensão de uma validade universal. 
A partir da fundação da Universidade de Berlim por Wilhelm von Humboldt (17671835) (BORSCHE, 1990), totalmente no sentido do Neo-Humanismo, isto é, com base na Antiguidade Clássica e suas línguas grega e latina, e com a finalidade de educar os homens de maneira mais ampla e extensa, destacando a cultura que se baseia na pesquisa em lugar de uma educação técnica e relacionada especialmente a disciplinas singulares, as ciências históricas e, sobretudo, os métodos históricos começaram a adquirir grande importância no sistema científico. Como nas ciências naturais e exatas, as ciências históricas defenderam um Objetivismo fundamental, pretendendo poder representar a realidade passada sem nenhuma limitação (OEXLE, 1984) - isto é valido para outras direções das ciências históricas no século XIX - a saber, as ciências históricas no sentido do Positivismo, defendidas na França, por exemplo, por Hippolyte Taine (1828-1893) e, na Alemanha, por Karl Lamprecht (1856-1915) (CHICKERING, 1995) ou no sentido do Materialismo Histórico, estabelecido por Karl Marx (1818-1883) (MARX, 1987, DAHRENDOPRF 1999, REIS 2000).. A base intelectual e cultural era o grande movimento do Historicismo no sentido amplo, enquanto uma das forças formadoras fundamentais da modernidade ao lado do Iluminismo, das revoluções políticas ou da industrialização (OEXLE, 1984). ${ }^{3}$

O próprio Wilhelm von Humboldt (HUMBOLDT, 1991) e, especialmente, Leopold von Ranke (1795-1886) tinham defendido nas suas teorias idealistas das ciências históricas a convicção de conhecimentos históricos objetivos. "O trabalho do historiador", segundo Humboldt, "é a descrição do que tinha acontecido" (HUMBOLDT, 1991, p. 40). Num primeiro passo, o historiador indaga, sem ser autoativo ou criativo, por meio de métodos empíricos, fatos fragmentários e isolados, mas ainda não pode conceber dessa maneira empírica um contexto interno causal entre eles. A tarefa ativa e criativa do historiador, num segundo passo, é, portanto, estabelecer esse contexto "por meio da sua própria força" (HUMBOLDT, 1991, p. 42). "É necessário, portanto,", conclui Humboldt, “[...] tomar ao mesmo tempo dois caminhos para aproximar-se da verdade histórica, a saber: a indagação exata, independente e crítica do que tinha acontecido e a combinação das coisas indagadas, ou seja, o pressentimento do que não pode ser atingido através daqueles meios" (HUMBOLDT, 1991, p. 43).

Essas duas partes, que são necessárias para conhecer a realidade histórica, já implicam que as forças criadoras na história não sejam exclusivamente reais, mas podem ser concebidas empiricamente, restando "um princípio, que tem efeitos mais poderosos e não ocorre diretamente na visibilidade, mas dá àquelas forças o impulso e a direção, a saber: o princípio das idéias, que, de acordo com a sua natureza, estão fora da finalidade, mas determinam a história universal em todas as suas partes" (HUMBOLDT, 1991, p. 56). Essas ideias, representando qualquer individualidade humana, as nações e as línguas ou, num nível mais alto, a beleza, a verdade e o direito (HUMBOLDT, 1991, p. 59s.), aspiram, como as forças verdadeiramente operantes diante da história, a realizar-se. "O trabalho do historiador na sua última, mas mais simples essência [Auflösung]", finalizou Humboldt, "é descrever a aspiração de uma idéia em atingir uma existência na realidade" (HUMBOLDT, 1991, p. 61).

Essa teoria idealista da história e das ciências históricas atribui, claramente, às ideias certa qualidade divina. "Para a vista humana, que pode lobrigar não diretamente os planos do governo mundial, mas apenas pressenti-los nas idéias pelas quais eles se manifestam, toda história é, por isso, somente a realização de uma idéia, e na idéia está, ao mesmo tempo, a força e a meta" (HUMBOLDT, 1991, p. 60). Por meio dessas ideias, forças transcendentais e metafísicas servem para explicar o processo histórico, enquanto em outras teorias como, por exemplo, no Positivismo ou no Materialismo Histórico, forças imanentes determinam o decorrer dos acontecimentos. Com a sua concepção de 
ideias como forças operantes na história, Wilhelm von Humboldt legou ao Historicismo alemão (TESSITORE, 1998) uma base histórico-religiosa, que foi desenvolvida mais tarde por Leopold von Ranke (HARDTWIG, 1991).

A Universidade de Berlim tornou-se o centro da historiografia crítica e científica com base nas fontes primárias na Alemanha. O representante mais importante dessa direção era Leopold von Ranke, professor de História em Berlim desde 1825. O objetivo principal de qualquer historiador era, como o próprio Ranke escreveu em 1824, "mostrar como tinha sido verdadeiramente" (RANKE apud OEXLE, 1984, p. 38), ou seja, descrever tanto objetiva quanto possivelmente a realidade histórica - com base, nas fontes primárias e na sua interpretação crítica e científica por meio da hermenêutica e do método históricofilológico, recentemente desenvolvido e aplicado por cientistas em disciplinas diferentes (IGGERS, 1978), como Friedrich August Wolf (1759-1824) (GRAFTON, 1986) na filologia clássica, Barthold Georg Niebuhr (1776-1831) na história antiga, Friedrich Schleiermacher (1768-1834) na teologia e Friedrich Carl von Savigny (1779-1861) e Karl Friedrich Eichhorn (178-1854) no direito. Eles compartilharam, além de uma significativa lealdade com a monarquia prussiana e a sua burocracia esclarecida, uma concepção semelhante das ciências humanas e salientaram a importância do princípio hermenêutico e histórico.

Ao contrário de Georg Wilhelm Friedrich Hegel (1770-1831) (HEGEL, 1985), que tinha destacado a unidade da história universal e a considerado um processo racional, no qual o Espírito do Mundo se desenvolve em formas sempre mais racionais e, por isso, acontece um progresso (BARUZZI, 1991, BAUMGART, 1995 e HEGEL, 1999), Ranke renuncia (ou anuncia?), na sua primeira conferência Sobre as épocas da história mais nova perante o rei bávaro Maximilian II (1811-1864, rei desde 1848), um progresso no sentido "[...] de que toda humanidade se desenvolve de um certo estado original para um objetivo positivo" (RANKE, 1982, p. 5). A história, porém, realiza-se, seguindo Humboldt, através de individualidades de valor igual. Portanto, a última manifestação não é melhor do que as anteriores, mas, como a frase mais famosa de Ranke diz, "qualquer época está diretamente em relação com Deus e o seu valor não se baseia de modo algum no que resulta dela, mas na sua própria existência, no seu próprio mesmo" (RANKE, 1982, p. 5).

Apesar da singularidade das individualidades, a história universal da humanidade não é somente uma coleção de fatos soltos, existentes lado a lado, mas tem "uma necessidade interna de seqüência" (RANKE, 1982, p. 8, IGGERS, 1978). Ranke explica: "Do ponto de vista da idéia divina, posso imaginar a questão de qualquer outra maneira acerca da humanidade conter uma variedade infinita de desenvolvimentos os quais, sucessivamente, se manifestam e, nomeadamente, de acordo com leis que são desconhecidas por nós, mais misteriosas e maiores do que se acha" (RANKE, 1982, p. 9). Em cada uma das épocas da humanidade, as diferentes grandes tendências mentais (die grossen geistigen Tendenzen), ou seja, as ideias dirigentes (leitende Ideen) se manifestam e caracterizam significativamente esse período. ${ }^{4} \mathrm{Na}$ sequência dessas "tendências dominantes" (die herrschenden Tendenzen), que, "[...] entretanto somente podem ser descritas, mas não podem ser somadas em instância última" (RANKE, 1982, p. 9), consiste o movimento permanente da humanidade.

Devido a essa fundamentação transcendental e metafísica da história, existe em Ranke também a ideia de "certo progresso [...], mas não gostaria de afirmar, que o mesmo se move numa linha direta, mas sim mais como um rio que abre o seu caminho de sua própria maneira" (RANKE, 1982, p. 8). E, por isso, Ranke aceita "a idéia da educação do gênero humano" como "verdadeira" (RANKE, 1982, p. 8) e reconhece "um progresso [...] em tudo o que se refere tanto ao conhecimento como à dominação da natureza" (RANKE, 
1982, p. 11) e "um progresso absoluto", "quanto às relações materiais, isto é, na formação e aplicação das ciências exatas e, da mesma maneira, em trazer as nações e os indivíduos diferentes para a idéia da humanidade e da cultura" (RANKE, 1982, p. 9s.). Em relação à arte e à literatura, às grandes ideias morais e religiosas e, em geral, às ideias da humanidade, Ranke reconhece somente um progresso no sentido extensivo ou expansivo, isto é, que sempre mais pessoas possam participar delas, concedendo "[...] que as idéias anteriores à moral ainda eram imperfeitas, mas, desde o cristianismo, tenha surgido, e junto com ele, a moralidade e a religião verdadeira haviam aparecido, nesse ponto nenhum progresso não pôde realizar-se mais" (RANKE, 1982, p. 11).

Os conceitos científicos então predominantes na segunda metade do século XIX, quando Nietzsche vivia e começou a escrever - tanto nas ciências naturais e exatas, representadas por Rudolf Virchow, quanto nas ciências históricas, preparadas por Wilhelm von Humboldt e representadas por Leopold von Ranke -, eram caracterizadas pela fundamentação religiosa, pela ideia de um progresso permanente e pela conviç̧ão de um conhecimento objetivo. "Contra essas duas manifestações do Objetivismo científico, o das ciências naturais e o das ciências históricas, nasceu com Friedrich Nietsche um adversário apaixonado. Contra o otimismo científico das ciências naturais e históricas, Nietzsche respondeu com um pessimismo científico radical" (OEXLE, 1984, p. 24).

Nietzsche foi nomeado no dia 13 de fevereiro de 1869 professor extraordinário de Filologia Clássica na Universidade de Basiléia com somente 24 anos de idade, onde ele, na primeira fase, desenvolvia uma grande variedade e multiplicidade de atividades profissionais, raciocinando ainda sobre os fundamentos e a justificativa da filologia (GERHARDT, 1999). Devido às conversas intensivas, desde 1869, com Richard Wagner (1813-1883) (WAPNEWSKI, 1999), o famoso compositor alemão, que defendia ideias de uma nova política cultural na Alemanha, culminando no estabelecimento do Festival de Ópera de Bayreuth, aberto no dia 13 de agosto de 1876 com a presença do Imperador alemão e do rei bávaro, Nietzsche ocupava-se também com questões atuais da cultura alemã. Nessa tensão intelectual entre antiguidade grega e atualidade alemã, entre filologia e política cultural, o primeiro escrito independente de Nietzsche, intitulado Die Geburt der Tragödie aus dem Geiste der Musik (NIETZSCHE, 1988/1999, p. 9-156) ${ }^{5}$ (O Nascimento da tragédia do espírito da música) de 1872 e dedicado a Wagner, tem que ser colocado, porque apresentou a cultura grega como projeto contrário e modelar em relação às condições atuais da Alemanha. Distanciando-se do ambiente científico e universitário e começando a formar a sua própria e inconfundível filosofia com o intuito de ensinar e educar os seus contemporâneos (GERHARDT, 1999), Nietzsche projetou compor as suas quatro Unzeitgemässen Betrachtungen (NIETZSCHE, 1988/1999 e s/d) (Considerações Extemporâneas) dos anos 1873/1874, criticando nelas - do ponto de vista de uma pessoa fora do seu próprio tempo - tendências intelectuais e culturais, políticas e filosóficas, predominantes no Império Alemão, recentemente fundado depois das Guerras entre a Alemanha e a França (1870/1871) (NIPPEREY, 1994 e 1994/1995). Enquanto Nietzsche parodia sarcasticamente, na primeira Consideração Extemporânea, a fé liberal no progresso na figura do filisteu culto David (Friedrich) Strauss, o devoto e o escritor (GERHARDT, 1999) ${ }^{6}$, e trata, na terceira, intitulada Schopenhauer como educador, sobre o pensador e filósofo autêntico, vivendo pessoalmente a sua filosofia (NEMEC, 1999) ${ }^{7}$ e, na quarta, intitulada Richard Wagner em Bayreuth e publicada com certo retardo somente em 1876, do indivíduo único e o gênio do compositor, mas já distanciando-se e emancipando-se do Mestre $^{8}$, reflete filosoficamente, repetindo a sua crítica contundente, na segunda, mais famosa e, mesmo assim, pelo próprio Nietzsche menosprezada (SALAQUARDA, 1984), Consideração Extemporânea, intitulada Da 
utilidade e desvantagem da história para a vida, a questão da cultura alemã em foco nas ciências históricas, que representam o pensamento do seu tempo significativamente (GERHARDT, 1999).

Nessa segunda Consideração contemporânea, Nietzsche se enfrenta diretamente com a concepção das ciências, predominante no seu tempo. A ciência somente considera uma perspectiva verdadeira e justa, ou seja, científica,

[...] que vê por todo o lado um fenômeno nascido, um fenômeno histórico e nunca um existente, um eterno; vive em um estado de hostilidade secreta contra os poderes imortalizantes da arte e da religião, da mesma forma que odeia o esquecimento, a morte do saber, e que tenta suprimir todos os limites do horizonte e lançar o homem em um mar infinito e ilimitado, de ondas luminosas e do devir conhecido (NIETZSCHE, $1988 / 1999$, p. 330 e s/d, p. 201).

Apesar do seu ataque direto às ciências, Nietzsche distingue, de maneira muito perspicaz, dois níveis diferentes de argumentação. À pergunta se a vida deveria prevalecer sobre a ciência ou a ciência sobre a vida, Nietzsche responde com toda a veemência: "A vida é o poder superior e dominante, porque um conhecimento, que destruísse a vida, destruir-se-ia também automaticamente. O conhecimento supõe a vida, ele tem pela conservação da vida o mesmo interesse que qualquer ser tem pela sua existência" (NIETZSCHE, 1988/1999, p. 330 e s/d, p. 202).

Focalizando, especialmente, a história e a historiografia nessa Segunda Consideração Extemporânea de 1874, Friedrich Nietzsche não quis fornecer uma outra contribuição para a discussão teórica dentro da ciência histórica sobre os seus conteúdos, métodos e objetivos, como já tinham feito Wilhelm von Humboldt, que fundamentou a historiografia na base do Idealismo, Leopold von Ranke, o historiador prussiano e fundador do método crítico na historiografia alemã, e outros representantes da historiografia científico-burguesa (IGGERS, 19978), os quais, a seguir Humboldt, realizaram esse Historicismo idealista exemplarmente, como também Karl Marx, Friedrich Engels (1820-1895) e os seus adeptos, cujo conceito de história e historiografia baseia-se no Materialismo Histórico. ${ }^{9} \mathrm{O}$ ponto de partida de Nietzsche foi diferente: ele não era um especialista nas ciências históricas, mas refletia filosoficamente, como observador atento do seu tempo, acerca da história e da historiografia (1), sempre estendendo as suas considerações às questões fundamentais da cultura e educação (2) como das ciências em geral (3). O seu ponto de vista, portanto, ficava fora das ciências históricas e também acima delas. A base das suas reflexões era a vida presente e atual, o homem individual e ativo e a sua ação imediata. No âmago desses critérios, Nietzsche desenvolveu a sua crítica forte e radical das tendências culturais, educacionais e também científicas do seu tempo.

(1) Nietzsche não condenou totalmente a história. Já no prefácio dessa Segunda Consideração Extemporânea, que ele próprio apreciou por atrás com certa reserva (SALAQUARDA, 1984), ele constatou nitidamente: "Sem dúvida, temos necessidade da história, mas temos necessidade dela de uma maneira diferente" (NIETZSCHE, 1988/1999, p. 245 e s/d, p. 101). O filósofo criticou, especialmente, duas direções ou dimensões nas ciências históricas, que foram, à primeira vista, contraditórias, mas, verdadeiramente, caracterizavam os conceitos predominantes da história e da historiografia na segunda metade do século XIX sob a influência do Historicismo. Por um lado, os historiadores, pesquisando questões sempre mais específicas, recebem uma multiplicidade de resultados, mas falta coesão entre eles, a ordem e os critérios fixos de valorização. 
Dessa maneira, a história aparece como um processo permanente do nascer e do perecer, de modo que todos os períodos históricos têm o mesmo valor. Com isso, Nietzsche enfrentava-se diretamente, por exemplo, com Leopold von Ranke, segundo o qual a tarefa de qualquer historiador não é julgar o passado ou ensinar os contemporâneos por meio do passado em proveito das gerações futuras, mas "somente apontar, como tinha sido verdadeiramente" (RANKE apud OEXLE, 1984, p. 28). O princípio do nascer, que as ciências históricas revelam, prejudica o ser, isto é, a ação e a atividade do homem indivíduo no presente, visto que tudo na história universal torna-se, finalmente, relativo e válido da mesma maneira.

Essa validade igual de todos os acontecimentos históricos paralisa o homem moderno. Por outro lado, também a ideia de certo desenvolvimento na história universal faz o homem da última geração passivo e inativo. Ideias dessa natureza, a seguir a <filosofia evolutiva> de Hegel, segundo o qual o Espírito do mundo realiza-se na história, mas, em manifestações diferentes, eram também significativas nas ciências históricas alemãs da segunda metade do século XIX, dando-lhes o caráter de uma religião histórica (HARDTWIG, 1991).

Contra essa concepção de história e historiografia, que não servia à vida atual, ao homem indivíduo e à ação forte no presente, Nietzsche enfrenta a sua história monumental, tradicionalista e crítica, totalmente ao serviço da vida humana: a história monumental, mostrando aos homens atuais os exemplos de grandes homens do passado e os ensinando dessa maneira; a história tradicionalista, despertando no homem da atualidade uma atitude de conservar e venerar o passado e, por fim, de segurá-lo para a posteridade; a história crítica, processando, inquirindo e, finalmente, julgando o passado e, dessa maneira, possibilitando ao homem uma vida futura (HARDTWIG, 1991).

(2) Cada uma dessas três formas de história não enfraquece, mas fortalece a vida. Obviamente, contudo, é preciso utilizar esses tipos com moderação, uma vez que também um excesso de história prejudica a vida. E exatamente essa doença Nietzsche diagnosticou nos seus tempos, percebendo cedo um fenômeno que somente mais tarde foi conscientemente discutido e definido (OEXLE, 1984): o fenômeno do Historicismo, que tinha influência e importância em quase todas as áreas intelectuais. De fato, naquele tempo, as ciências históricas e uma tendência histórica em geral tinham uma posição predominante na vida científica, cultural e social. A ocupação com a história aumentou, certamente, a partir de 1870/1871, quando o (segundo) Império Alemão, fundado recentemente, depois da vitória contra a França, tinha que provar a sua longa tradição. Esse sentido histórico, tornado para trás, sugerindo aos contemporâneos uma convicção de pertencer a uma geração atrasada e decadente, destrói a <força plástica> do homem, isto é, a sua faculdade de viver e agir ativamente no presente.

A cultura alemã, Nietzsche julga, sofre fortemente dessa doença histórica, que é transmitida já nas escolas. Os professores ensinam, por um lado, uma multiplicidade de fatos e conhecimentos, mas falta aos alunos o espírito e o interesse pelo específico, grande e extraordinário. Dessa maneira:

Nós homens modernos percorremos os museus e assistimos aos concertos. Sente-se bem que uma coisa tem um som diferente do outro, tem efeitos diferentes da outra; perder progressivamente a impressão de que se é em toda a parte um estrangeiro, deixar de admirar algo demais, finalmente, aceitar tudo - isso se chama, obviamente, o sentido histórico, a cultura histórica (NIETZSCHE, 1988/1999, p. 299 e s/d, p. 167). 
A aplicação e a realização dessa forma de história nas escolas enfraquece a personalidade de jovens e produz homens fracos. Os mesmos efeitos têm, por outro lado, a admiração exagerada do passado e dos seus exemplos.

Friedrich Nietzsche analisa, de maneira muito clara, as consequências extensas dessa doença histórica para a cultura e a educação na Alemanha e para além. A falta da faculdade de valorização dos fatos históricos como também a falta da consciência do seu valor entre os pretensos epígonos paralisam a <força plástica $>$ dos homens modernos. Por isso, a cultura alemã, orientada quase que exclusivamente pela mediocridade, proíbe a gênese do grande. Os homens fracos da modernidade são produzidos nas escolas. Consequentemente, Nietzsche estende, portanto, a sua crítica da história por cima da cultura "ao ensino escolar, protestando contra a formação dos jovens do homem moderno na história" (NIETZSCHE, 1988/1999. p. 325 e s/d, p. 195s.; LIPPERHEIDE, 1999)). Sem reformas nas escolas, a cultura alemã não pode ser melhorada. A posição-chave nessa crítica à cultura, porém, está na história, se ela serve à vida ou não. Enquanto não acontecer essa reforma fundamental nas escolas, somente a força da juventude poderá trazer uma solução sucessiva no decorrer dos tempos (NIETZSCHE, 1988/1999, p. 324-330 e s/d, p. 195-201. ${ }^{10}$ Nesse sentido, Friedrich Nietzsche mostra-se um otimista nessa Segunda Consideração Extemporânea, um otimista cínico.

(3) Finalmente, Friedrich Nietzsche contribuiu com essa Segunda Consideração Extemporânea para a discussão sobre os fundamentos teóricos das ciências, uma contribuição muito importante, que somente pode ser esboçada aqui. A base do conhecimento científico (CASSIRER, 1973/1974), tanto quanto às ciências naturais como às ciências históricas, na época do Positivismo e do Historicismo, pelo menos desde a década de trinta do século XIX, era o Objetivismo, pretendendo um conhecimento absoluto e objetivo, que representa, verdadeiramente, a realidade da natureza ou do passado. Essa certeza epistemológica, tendo validade quase sem limitações, produzia uma fé em um progresso e, com isso, uma confiança forte em um futuro melhor. Contrapondose a esse otimismo ingênuo das ciências, Nietzsche criticava, com toda a veemência, essa pretensão das ciências de conhecer verdadeiramente e objetivamente as realidades (LIPPERHEIDE, 1999). Mas a sua crítica, proferida desde um ponto de vista filosófico, ou seja, fora das ciências, não tinha efeitos (OEXLE, 1984). ${ }^{11}$

Os limites do conhecimento já tinham sido destacados por outras tradições epistemológicas que se desenvolveram a partir da Baixa Idade Média e atingido o seu apogeu provisório no fim do século XVIII, quando Immanuel Kant (1724-1804) (VORLAENDER, 1924/1993 e HÖFFE, 2000) apresentou um resumo dessas tradições no prefácio da segunda edição da sua Crítica da razão pura (KANT, 1983) de 1787, descrevendo o processo do conhecimento científico através da metáfora de um interrogatório das testemunhas (KANT, 1983 e OEXLE, 1984). Essa tradição foi retomada por Max Weber (1864-1920) (KAESSLER, 1999), o famoso sociólogo alemão, no seu escrito intitulado Wissenschaft als Beruf (WEBER, 1999) de 1919 e continuado por outros cientistas naturais, especialmente da área da física: Albert Einstein (1879-1955) com a sua famosa teoria de relatividade [= Relativitätstheorie], Werner Heisenberg (1901-1976) com a sua relação de incerteza [= Unschärferelation], segundo a qual, na física atômica, os fenômenos observados somente se constituem pela observação, ou seja, o conhecimento físico não é absoluto, mas relacional, e Niels Bohr (1885-962) com a sua ideia de complementaridade [= Komplementarität], segundo a qual duas teorias contrárias podem existir concomitantemente sobre a mesma coisa. Salientou, nas suas reflexões teóricas, obviamente, a seguir à teoria da ciência e do conhecimento do século XVIII, a limitação do conhecimento científico (OEXLE, 1984). 
Friedrich Nietzsche representa uma ponte nessa discussão, mas, como filósofo e, com isso, como que fora das ciências, sem poder deixar traços profundos na história da ciência.

\section{Referências}

BARUZZI, Arno: Georg Wilhelm Friedrich Hegel, In: MAIER, Hans; RAUSCH, Heinz; DENZER, Horst (Orgs.). Klassiker des politischen Denkens. v. 2. Von Locke bis Weber, München: Verlag C. H. Beck, 1968, p 187-216;

BAUMGART, Peter. Fortschritt der Geschichte - Geschichte als Fortschritt? In: BAUMGARTNER, Hans Michael; BÖHM, Winfried; LINDAUER, Martin (Orgs.). Fortschritt als Schicksal? - Weder Verheissung noch Verhängnis? 8. Würzburger Symposium der Universität Würzburg, Stuttgart/Düsseldorf/Leipzig: Ernst Klett Verlag, 1995. p. 333-346.

BORSCHE, Tilman. Wilhelm von Humboldt (Beck'sche Reihe 519), München: Verlag C. H. Beck, 1990.

CASSIRER, Ernst. Das Erkenntnisproblem in der Philosophie und Wissenschaft der neueren Zeit. 4 v. Darmstadt: Wissenschaftliche Buchgesellschaft. 1973/1974 (original 1906-1932).

CHICKERING, Roger. Der Leipziger Positivismus. In: FUCHS, Eckhardt; SAMMLER, Steffen (Orgs.). Geschichtswissenschaft neben dem Historismus (Comparativ. Leipziger Beiträge zur Universalgeschichte und vergleichenden Gesellschaftsforschung. Ano 5, n. 3), Leipzig: Leipziger Universitäts-Verlag 1995. p. 20-31.

COMTE, Auguste: Curso de filosofia positiva, etc. Seleção de textos: José Arthur Giannotti. 2. ed. Trad.: J. A. Giannotti/Miguel Lemos. São Paulo: Abril Cultural, 1983. (Os Pensadores).

DAHRENDORF, Ralf. Karl Marx (1818 - 1883). In: KAESSLER, Dirk (Org.). Klassiker der Soziologie. v. 1: Von Auguste Comte bis Norbert Elias, München: Verlag C. H. Beck, 1999. p. 58-73.

GERHARDT, Volker. Friedrich Nietzsche (Beck'sche Reihe. v. 522. Denker). 3. ed. München: Verlag C. H. Beck, 1999 (1992).

GRAFTON, Anthony. "Man muss aus der Gegenwart heraussteigen": History, Tradition, and Traditions of Historical Thought. In: BÖDEKER, Hans-Erich (Org.). Aufklärung und Geschichte. Studien zur deutschen Geschichtswissenschaft im 18. Jahrhundert (Veröffeentlichungen des Max-Planck-Instituts für Geschichte. Vol. 81), Göttingen: Vandenhoek \& Ruprecht, 1986. p. 416-429.

HARDTWIG, Wolfgang. Geschichtsreligion - Wissenschaft als Arbeit - Objektivität. In: Historische Zeitschrift, v. 252, p. 1-31, 1991. 
HEGEL, Georg Wilhelm Friedrich. A fenomenologia do espírito, etc. Trad. Henrique Cláudio de Lima Vaz/Orlando Vitorino/Antônio Pinto de Carvalho. 3 ed. São Paulo: Abril Cultural, 1985. (Os Pensadores).

Filosofia da História. Trad.: Maria Rodrigues e Hans Harden. 2. ed. Brasília, DF: Editora UnB, 1999.

HÖFFE, Otfried. Immanuel Kant. 5. ed. (Beck'sche Reihe. Vol. 506), München: C. H. Beck, 2000.

HUMBOLDT, Wilhelm von: Über die Aufgabe eines Geschichtsschreibers (1821), in: RIEDEL, Manfred (Org.). 19. Jahrhundert. Positivismus, Historismus, Hermeneutik. Geschichte der Philosophie in Text und Darstellung, Stuttgart: Philipp Reclam, v. 7, jun. 1991, p. 40-66.

HUSSERL, Edmund. Die Krise der europäischen Wissenschaften und die transzendentale Phänomenologie. Hamburg: Philosophische Bibliothek, 1977.

IGGERS, Georg G. Neue Geschichtswissenschaft. Vom Historismus zur historischen Sozialwissenschaft. München: Deutscher Taschenbuchverlag, 1978. (Original em inglês, 1975).

KAESSLER, Dirk: Max Weber. In: KAESSLER, Dirk (Org.), Klassiker der Soziologie. v. 1: Von Auguste Comte bis Norbert Elias, München: Verlag C. H. Beck, 1999. , p. 190212.

KANT, Immanuel. Crítica da razão pura. Trad.: Valerian Rohden, Udo Baldur Moosburger, 2. ed. São Paulo: Victor Civita, 1983. (Os Pensadores: KANT (I)).

LEUSCHNER, Peter: Auguste Comte. IN: In: MAIER, Hans; RAUSCH, Heinz; DENZER, Horst (Orgs.). Klassiker des politischen Denkens. v. 2. Von Locke bis Weber, München: Verlag C. H. Beck, 1968, p. 262-287.

LIPPERHEIDE, Christian. Nietzsches Geschichtsstrategien. Die rhetorische Neuorganisation der Geschichte. (Nietzsche in der Diskussion). Würzburg: Königshausen \& Neumann, 1999.

MAIER, Hans; RAUSCH, Heinz; DENZER, Horst (Orgs.). Klassiker des politischen Denkens. v. 2. Von Locke bis Weber, München: Verlag C. H. Beck, 1968.

MARTON, Scarlett. Nietzsche: a transvaloração dos valores. São Paulo: Moderna, 1993. (Coleção Logos).

MARX, Karl: Manuscritos econômico-filosóficos, etc. Seleção de textos: José Arthur Giannotti. Trad.: José Carlos Bruni/J. A. Giannotti/Edgard Malagodi. São Paulo: Nova Cultural, 1987 (Os Pensadores).

NEMEC, Friedrich. Nietzsche, Friedrich. In: Neue Deutsche Biographie. Ed.: Historische Kommission der Bayerischen Akademie der Wissenschaften. v. 19, Berlin: Duncker \& Humblot, 1999. p. 249-253. 
NIETZSCHE, Friedrich. Die Geburt der Tragödie. Unzeitgemässe Betrachtungen I - IV. Nachgelassene Schriften 1870 - 1873 (Friedrich Nietzsche: Sämtliche Werke. Kritische Studienausgabe (KSA). Ed. De Giorgio COLLI e Mazzino MONTIINARI), 2a edição, München: Deutscher Taschenbuch Verlag 1988/1999.

. Considerações intempestivas. Trad.: Lemos de Azevedo (Coleção Síntese. Vol. 23), Lisboa: Presença/São Paulo: Martins Fontes, s/d.

NIPPERDEY, Thomas. Deutsche Geschichte. 1800 - 1866. München: Verlag C. H. Beck, 1994. $1994 / 1995$.

Deutsche Geschichte 1866 - 1918. 2 vols. München: Verlag C. H. Beck,

OEXLE, Otto Gerhard. Die Geschichtswissenschaft im Zeichen des Historismus. Bemerkungen zum Standort der Geschichtsforschung. In: Historische Zeitschrift, v. 238, p. 17-55, 1984.

POPPER, Karl. Das Elend des Historizismus. 6. ed. revis. (Die Einheit der Gesellschaftswissenschaften. v. 3). Tübingen: J.C.B. Mohr, 1987. (Original em inglês, 1957, 2. ed. 1960).

RANKE, Leopold Von. Über die Epochen der neueren Geschichte. Vorträge, dem König Maximilian von Bayern gehalten, Darmstadt: Wissenschaftliche Buchgesellschaft, 1982.

RAUSCH, Heinz: John Stuart Mill. In: MAIER, Hans; RAUSCH, Heinz; DENZER, Horst (Orgs.). Klassiker des politischen Denkens. v. 2. Von Locke bis Weber, München: Verlag C. H. Beck, 1968, p. 240-261.

REIS, José Carlos. História e verdade. Posições. Síntese. Revista de Filosofia, v. 27, n. 89, p. 321-348, 2000.

SALAQUARDA, Jörg: Studien zur zweiten unzeitgemässen Betrachtung. In: NietzscheStudien. Internationales Jahrbuch für die Nietzsche-Forschung, v. 13, p. 1-45, 1984.

SCHIPPERGES, Heinrich: Artigo Virchow, Rudolf. In: Deutsche Biographische Enzyklopädie. Org. de Walter KILLY e Rudolf VIERHAUS. v. 1, München: Verlag K. G. Saur, 1999, p. 213-214.

TESSITORE, Fulvio. Wilhelm von Humboldt und der Historismus. Nürnberg: Helmut Seubert Verlag, 1998.

VORLÄNDER, Karl. Immanuel Kant. Der Mann und das Werk. 3. ed. ampliada. Stuttgart: Felix Meiner Verlag, 1993. (Leipzig, 1924).

WAPNEWSKI, Peter: Artigo Wagner, Richard, in: Deutsche Biographische Enzyklopädie. Org. de Walter KILLY e Rudolf VIERHAUS. v. 1, München: Verlag K. G. Saur, 1999, p. 2860287.

WEBER, Max: Ciência e política. Duas vocações. São Paulo: Cultrix, 1999. 


\section{Notas}

${ }^{1}$ Dr. Peter Johann Mainka, M. A., Institut für Geschichte der Universität Würzburg (= Instituto de História da Universidade de Würzburg)/Alemanha.

${ }^{2}$ Impresso in: NIETZSCHE, KSA I, 1999, p. 243-334 (citado em seguida: UB II). Uma tradução para o português encontra-se in: NIETZSCHE: Considerações Intempestivas, s/d, p. 101-205 e p. 210 (notas) (citado em seguida: CI II). As citações traduzidas de UB II baseiam-se na tradução portuguesa de CI II, mas são modificadas pelo autor quando pareceu necessário.

${ }^{3}$ Um crítico forte do Historicismo, entendido como "posição diante das ciências sociais [...] supondo que prognóstico histórico seja o objetivo principal delas e que esse objetivo pode ser atingido através de que descobre-se os <ritmos> ou os <patterns>, as <leis> ou as <tendências>, que estão na base do desenvolvimento histórico", era Karl POPPER, 1987, p. 2.

${ }^{4}$ Em outro lugar, Ranke designa essas tendências ou ideias como entidades mentais (geistige Wesenheiten) ou pensamentos de Deus (Gedanken Gottes), citado in: OEXLE, 1984, p. 39.

${ }^{5}$ Esse escrito foi em 1886, reeditado pelo próprio Nietzsche sob o título: Die Geburt der Tragödie. Oder: Griechenthum und Pessimismus.

6 Impresso sob o título original David Strauss, der Bekenner und der Schriftsteller, in: NIETZSCHE, 1988/1999. p. 157-242, traduzido para o português, in: NIETZSCHE, s/d, p. 7-100 e 209s. (notas).

${ }^{7}$ Impresso sob o título original Schopenhauer als Erzieher, in: NIETZSCHE, 1988/1999, p. 335-427.

${ }^{8}$ Impresso sob o título original Richard Wagner in Bayreuth, in: NIETSCHE: 1988/1999, p. 429-510.

9 Todos esses diferentes conceitos de história, também o do Materialismo Histórico, que pressupõe uma consequência necessária de formações sociais no processo histórico, a saber, da sociedade dos donos de escravos (Slavenhaltergesellschaft), por cima do Feudalismo e Capitalismo, finalmente, ao Comunismo, e, por isso, também defende certo determinismo na história, têm uma qualidade quase religiosa e podem ser caracterizados como "religiões de história" (HARDTWIG, 1991).

${ }^{10}$ Nesse trecho, NIETZSCHE dá o seguinte exemplo: "surgiu na Alemanha, ainda não há um século, entre alguns jovens a intuição daquilo, a que se chama a poesia [...] Talvez agora haja cem homens mais do que havia a cem anos, que saibam o que é a poesia; talvez haja, cem anos mais tarde, mais cem homens que tenham aprendido o que é a cultura e que os alemães não tiveram cultura até então, mesmo que eles a tenham discutido extensamente e tenham se gabado com ela".

${ }^{11}$ No ano de 1936, o filósofo Edmund Husserl (1859-1938) também questionava o Objetivismo das ciências naturais e humanas, mas a sua crítica ficava igualmente sem efeitos, cf. HUSSERL, 1977.

Recebido em outubro-13

Aprovado em novembro-13 